\title{
On the Impact Origin of Phobos and Deimos. III. Resulting Composition from Different Impactors
}

\author{
Francesco C. Pignatale ${ }^{1}$ (i), Sébastien Charnoz ${ }^{1,2}$ (i), Pascal Rosenblatt ${ }^{3,4}$, Ryuki Hyodo ${ }^{5}$, Tomoki Nakamura ${ }^{6}$, and Hidenori Genda \\ ${ }^{1}$ Institut de Physique du Globe de Paris (IPGP), 1 rue Jussieu, F-75005, Paris, France; pignatale@ipgp.fr \\ ${ }^{2}$ Institut de Physique du Globe/Universite Paris Diderot/CEA/CNRS, F-75005 Paris, France \\ Royal Observatory of Belgium, Avenue circulaire 3, B-1180 Uccle, Belgium \\ ${ }^{4}$ Now at ACRI-ST, 260 route du pin-montard-BP 234, F-06904 Sophia-Antipolis Cedex, France \\ ${ }^{5}$ Earth-Life Science Institute/Tokyo Institute of Technology, 152-8550 Tokyo, Japan \\ ${ }^{6}$ Tohoku University, 980-8578 Miyagi, Japan \\ Received 2017 November 10; revised 2017 December 12; accepted 2017 December 13; published 2018 January 30
}

\begin{abstract}
The origin of Phobos and Deimos in a giant impact-generated disk is gaining larger attention. Although this scenario has been the subject of many studies, an evaluation of the chemical composition of the Mars's moons in this framework is missing. The chemical composition of Phobos and Deimos is unconstrained. The large uncertainties about the origin of the mid-infrared features; the lack of absorption bands in the visible and nearinfrared spectra; and the effects of secondary processes on the moons' surfaces make the determination of their composition very difficult using remote sensing data. Simulations suggest a formation of a disk made of gas and melt with their composition linked to the nature of the impactor and Mars. Using thermodynamic equilibrium, we investigate the composition of dust (condensates from gas) and solids (from a cooling melt) that result from different types of Mars impactors (Mars-, CI-, CV-, EH-, and comet-like). Our calculations show a wide range of possible chemical compositions and noticeable differences between dust and solids, depending on the considered impactors. Assuming that Phobos and Deimos resulted from the accretion and mixing of dust and solids, we find that the derived assemblage (dust-rich in metallic iron, sulfides and/or carbon, and quenched solids rich in silicates) can be compatible with the observations. The JAXA's Martian Moons eXploration (MMX) mission will investigate the physical and chemical properties of Phobos and Deimos, especially sampling from Phobos, before returning to Earth. Our results could be then used to disentangle the origin and chemical composition of the pristine body that hit Mars and suggest guidelines for helping in the analysis of the returned samples.
\end{abstract}

Key words: planets and satellites: composition - planets and satellites: formation - planets and satellites: individual (Phobos, Deimos)

\section{Introduction}

The history of the formation of Mars's moons, Phobos and Deimos, is still an open question. It has been the subject of several studies that point to a capture origin, in situ or impactgenerated formation (Rosenblatt 2011; Citron et al. 2015; Rosenblatt et al. 2016, and references therein). Accretion within an impact-generated disk scenario (Craddock 2011; Rosenblatt et al. 2016) is gaining more support, as it can explains several properties of the Mars's moons, such as the mass and the orbital parameters (Rosenblatt et al. 2016; Hesselbrock \& Minton 2017; Hyodo et al. 2017a, 2017b).

Phobos has a very peculiar infrared spectra. Although midinfrared (MIDIR) show different features, the visible (VIS) and near-infrared (NIR) spectra are characterized by a lack of absorption features (Murchie 1999; Giuranna et al. 2011; Rosenblatt 2011; Murchie et al. 2015). Murchie (1999) isolated two main regions named "red" and "blue" on the surface of Phobos that have different spectral characteristics that can be best matched by D- and T-type asteroids, respectively (Murchie et al. 1991; Murchie 1999; Rivkin et al. 2002). Giuranna et al. (2011) presented a detailed investigation on the possible chemistry of Phobos's surface. They found that the "blue" region can be fitted with a phyllosilicates-rich material, while the "red" region has a best fit when tectosilicates, mainly feldspar, are included in the model. Moreover, they found that no class of chondritic material can match the observed spectra.
Nevertheless, they pointed out that different more complex mixtures of dust could be able to reproduce the observed trends.

The featureless VIS-NIR spectra are often associated with a strong space weathering (Murchie 1999; Rosenblatt 2011). However, Giuranna et al. (2011) following the spectroscopical studies of Singer (1981), Salisbury \& Walter (1989), Cloutis et al. (1990a, 1990b, 1990c, 1990d), Burns (1993), and Klima et al. (2007) list a series of possible mechanisms that can reduce the strength of the spectra and match the observation: (i) as the $1-2 \mu \mathrm{m}$ feature arise from iron-bearing material such as pyroxene and olivine, the absence of those compounds may reduce the spectra; (ii) a mixture of opaque material such as metallic iron, iron oxides, and amorphous carbon mixed with olivine and pyroxene can reduce dramatically the VIS/NIR bands; (iii) solids that result from quenching from the liquids state may have their reflectance properties reduced as they lack of perfect crystalline structure; and (iv) the reflectance of finegrain materials decreases as the size of the grains decreases.

Hyodo et al. (2017a) presented detailed smoothed particle hydrodynamics (SPH) simulations in which they determined the dynamical, physical and thermodynamical properties of an impact-generated disk. They found that the material that populate the disk is initially a mixture of gas $(\sim 5 \%)$ and melts ( $95 \%)$. This information together with the Martian composition and hypothesis on the impactors, can be used for modeling the building blocks of Phobos and Deimos. 
In this work, we present a study of the bulk composition of the Mars's moons following the giant-impact scenario. Our aim is to provide more clues on the origin of the moons, their chemical composition, infrared spectra, and the nature of the impactor itself.

Furthermore, the JAXA's $\mathrm{MMX}^{7}$ mission plans to observe Phobos and Deimos in detail, and return samples (at least $10 \mathrm{~g}$ ) from the surface of Phobos. Our results could be then used as guidelines for helping in their analysis and interpretation.

Starting from different initial compositions of the impactor (from Mars-like to chondritic-like), we compute thermodynamic equilibrium (DeHoff 1993) to solve for stable phases that may condense from the gas in the impact-generated disk. Additionally, we compute the composition of the cooling melt to investigate how it will eventually differs from condensates. The resulting condensates and solidified melt are then taken as proxies for the building block of Phobos and Deimos and further discussion are made.

In this work, we will mainly focus on Phobos, as more observations are available and as it will be the main sampling target of the JAXA's MMX mission. Nevertheless, the formation of Deimos follows the same proposed scenario.

The paper is structured as follows. In Section 2, we describe the techniques and the model we use in our calculations. In Section 3, we present our results that will be discussed in Section 4. Conclusions are summarized in Section 5.

\section{Model and Methods}

Hyodo et al. (2017a) calculated that the temperature in the Mars's moon-forming region of the disk reaches $T \sim 2000 \mathrm{~K}$ just after the impact. The value of $P \sim 10^{-4}$ bar is chosen as our fiducial pressure as it is, for the given temperature, the average saturation pressure for several mixtures calculated in Visscher \& Fegley (2013) and the average pressure in the disk profile in Ronnet et al. (2016) and Hyodo et al. (2017a) where gas and melt coexist. Under these conditions, the material in the disk that comes from Mars and from the impactor will result in a mixture composed of gas and melt (Hyodo et al. 2017a).

Hyodo et al. (2017a) showed that the building blocks of Phobos and Deimos would be composed of a mixture of about half-Martian material and half-impactor material. We thus assume that the gas is made of well-mixed two components: the gas that is released by heating up Mars material plus the gas that is released by heating up impactor material. We then assume that the melt is a mixture of the unvaporized material from the two bodies (Hyodo et al. 2017a). Figure 1 shows a cartoon of the proposed model.

As the disk cools, the gas will eventually re-condense and the melt will solidify. Here, for ease of understanding, we define dust as the condensates from the gas phase and solids as the material that result from the solidification of the melt.

To determine the composition of the dust that will condense from the gas phase, we assume thermodynamic equilibrium (DeHoff 1993): at constant temperature and pressure, the stability of a system is determined by its Gibbs free energy, and, in fact, by the composition which minimizes the potential of the system. Although it is an approximation, thermodynamic equilibrium is a powerful tool to understand the evolution of the chemical composition of complex systems. This technique has been extensively used in the study of the chemistry of gas

http://mmx.isas.jaxa.jp/en/index.html

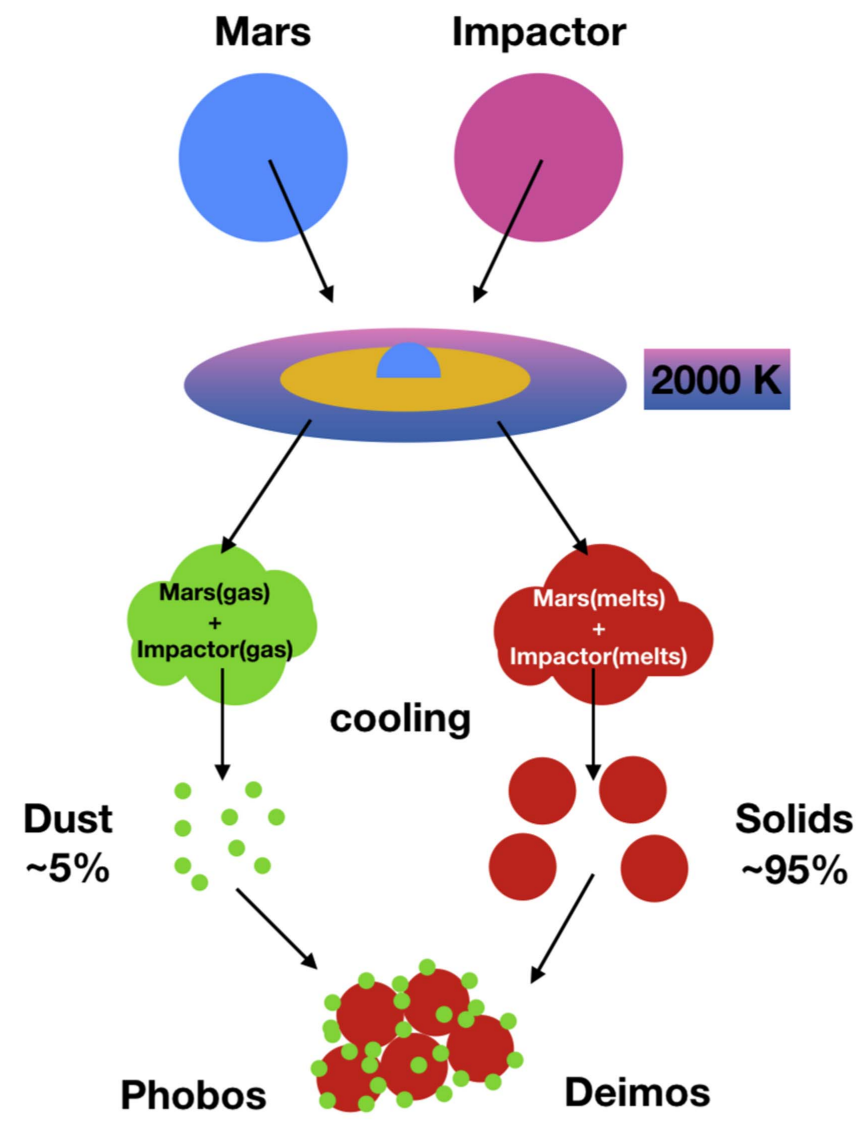

Phobos/Deimos forming region

Figure 1. Cartoon describing the considered scenario. After the impact, part of Mars material will be ejected out at high temperature and will vaporize into gas, as well as part of the impactor. The gas mixture will then condense into dust. On the other hand, the unvaporized material from Mars and the impactor will form a melt and then solidify. Phobos and Deimos will be the result of the accretion of these two components. The yellow region represents the part of disk within the Roche limit (Hyodo et al. 2017a).

and dust in several astrophysical environments: from the solar nebula, meteorites, and protoplanetary disks (Larimer 1979; Yoneda \& Grossman 1995; Lodders 2003; Ebel et al. 2006; Pignatale et al. 2016) to stars dusty envelopes (Gail \& Sedlmayr 1999; Lodders \& Fegley 1997; Ebel \& Grossman 2001) and exoplanets composition (Bond et al. 2010).

To compute the thermodynamic equilibrium, we use the HSC software package (version 8; Roine 2014), which includes the Gibbs free energy minimization method of White et al. (1958). Thermodynamic data for each compound are taken from the database provided by HSC (Roine 2014, and references therein). HSC has been widely used in materials science, and it has been already tested in astrophysics, showing very good reliability in predicting the composition of different systems (Pasek et al. 2005; Bond et al. 2010; Pignatale et al. 2011; Madhusudhan et al. 2012).

To calculate the composition of the solids from the cooling melts we use the normative mineralogy (CIPW-norm; Cross et al. 1902) and the work of Ronnet et al. (2016) as benchmark. CIPW-norm is one of the most-used technique to determine, in a first approximation, the equilibrium composition of a multicomponent melt (Cross et al. 1902). 
Table 1

Elemental Abundances (mol\%) for Single Impactors

\begin{tabular}{|c|c|c|c|c|c|c|}
\hline & Mars & $\mathrm{CV}$ & $\mathrm{CI}$ & EH & Comet & Sun \\
\hline Element & \multicolumn{6}{|c|}{ Abundances (mol\%) } \\
\hline $\mathrm{Al}$ & $1.250 \mathrm{E}+00$ & $1.356 \mathrm{E}+00$ & $4.668 \mathrm{E}-01$ & $7.596 \mathrm{E}-01$ & $7.000 \mathrm{E}-02$ & $2.82 \mathrm{E}-04$ \\
\hline $\mathrm{C}$ & $0.000 \mathrm{E}+00$ & $9.747 \mathrm{E}-01$ & $3.902 \mathrm{E}+00$ & $8.427 \mathrm{E}-01$ & $1.137 \mathrm{E}+01$ & $2.69 \mathrm{E}-02$ \\
\hline $\mathrm{Ca}$ & $9.300 \mathrm{E}-01$ & $9.911 \mathrm{E}-01$ & $3.362 \mathrm{E}-01$ & $5.367 \mathrm{E}-01$ & $6.000 \mathrm{E}-02$ & $2.19 \mathrm{E}-04$ \\
\hline $\mathrm{Fe}$ & $5.440 \mathrm{E}+00$ & $8.797 \mathrm{E}+00$ & $4.773 \mathrm{E}+00$ & $1.314 \mathrm{E}+01$ & $5.200 \mathrm{E}-01$ & $3.16 \mathrm{E}-03$ \\
\hline $\mathrm{H}$ & $0.000 \mathrm{E}+00$ & $5.808 \mathrm{E}+00$ & $2.906 \mathrm{E}+01$ & $0.000 \mathrm{E}+00$ & $5.464 \mathrm{E}+01$ & 99.9 \\
\hline K & $4.800 \mathrm{E}-02$ & $1.658 \mathrm{E}-02$ & $2.098 \mathrm{E}-02$ & $5.177 \mathrm{E}-02$ & $0.000 \mathrm{E}+00$ & $1.07 \mathrm{E}-05$ \\
\hline $\mathrm{Mg}$ & $1.632 \mathrm{E}+01$ & $1.247 \mathrm{E}+01$ & $5.845 \mathrm{E}+00$ & $1.104 \mathrm{E}+01$ & $9.900 \mathrm{E}-01$ & $3.98 \mathrm{E}-03$ \\
\hline $\mathrm{Na}$ & $7.000 \mathrm{E}-01$ & $3.001 \mathrm{E}-01$ & $3.121 \mathrm{E}-01$ & $7.484 \mathrm{E}-01$ & $1.000 \mathrm{E}-01$ & $1.74 \mathrm{E}-04$ \\
\hline $\mathrm{O}$ & $5.815 \mathrm{E}+01$ & $5.157 \mathrm{E}+01$ & $4.491 \mathrm{E}+01$ & $4.724 \mathrm{E}+01$ & $2.834 \mathrm{E}+01$ & $4.89 \mathrm{E}-02$ \\
\hline S & $0.000 \mathrm{E}+00$ & $1.434 \mathrm{E}+00$ & $2.695 \mathrm{E}+00$ & $4.577 \mathrm{E}+00$ & $7.100 \mathrm{E}-01$ & $1.32 \mathrm{E}-03$ \\
\hline $\mathrm{Si}$ & $1.673 \mathrm{E}+01$ & $1.624 \mathrm{E}+01$ & $7.656 \mathrm{E}+00$ & $2.104 \mathrm{E}+01$ & $1.830 \mathrm{E}+00$ & $3.23 \mathrm{E}-03$ \\
\hline $\mathrm{Ti}$ & $4.000 \mathrm{E}-02$ & $4.280 \mathrm{E}-02$ & $1.285 \mathrm{E}-02$ & $2.379 \mathrm{E}-02$ & $0.000 \mathrm{E}+00$ & $8.90 \mathrm{E}-06$ \\
\hline $\mathrm{Zn}$ & $2.000 \mathrm{E}-04$ & $3.709 \mathrm{E}-03$ & $6.988 \mathrm{E}-03$ & $9.674 \mathrm{E}-03$ & $0.000 \mathrm{E}+00$ & $3.63 \mathrm{E}-06$ \\
\hline $\mathrm{Mg} / \mathrm{Si}$ & 0.98 & 0.77 & 0.76 & 0.52 & 0.54 & 1.25 \\
\hline $\mathrm{Fe} / \mathrm{O}$ & 0.09 & 0.17 & 0.11 & 0.28 & 0.02 & 0.06 \\
\hline $\mathrm{Fe} / \mathrm{Si}$ & 0.33 & 0.54 & 0.62 & 0.62 & 0.28 & 0.98 \\
\hline$(\mathrm{Fe}+\mathrm{Si}) / \mathrm{O}$ & 0.38 & 0.49 & 0.28 & 0.72 & 0.08 & 0.13 \\
\hline $\mathrm{C} / \mathrm{O}$ & 0.00 & 0.02 & 0.09 & 0.02 & 0.40 & 0.54 \\
\hline $\mathrm{H} / \mathrm{O}$ & 0.00 & 0.11 & 0.65 & 0.00 & 1.93 & 2041 \\
\hline
\end{tabular}

Note. Abundances of the solar photosphere (Sun) are also shown.

(Hyodo et al. 2017a) showed that the melt phase of Mars and the impactor will likely never completely equilibrate between each other. Mars-only and impactor-only melt with different degrees of equilibration in between are indeed expected. Nevertheless, calculating the resulting compositions of a equilibrated melt represents a first interesting add-on to investigate the differences that condensation and solidification would bring to the final Phobos bulk composition. Moreover, our model suggests that the MMX may be confronted with two distinguishable family of material, the dust and the solids. As a consequence, this investigation can bring further information and clues that can be used in the MMX samples analysis.

During the planet formation, Mars and the other inner rocky planets experienced impacts with other bodies. Their impact histories strongly depend on the timing and location of the planets (Bottke \& Andrews-Hanna 2017; Brasser \& Mojzsis 2017; Brasser et al. 2017; Raymond \& Izidoro 2017). The nature of the impactors is unconstrained, as the dynamical interactions of Jupiter and Saturn with the surrounding minor bodies may have scattered and delivered in the inner solar system material of different nature and of chondritic origin (Brasser \& Mojzsis 2017; Raymond \& Izidoro 2017; Bottke \& Andrews-Hanna 2017). Our aim is to determine the changes that different impactors would bring in the chemical composition of Phobos, and if these differences can be traceable. To keep our selection as chemically heterogeneous as possible, we thus consider the following types of impactor: Mars type, $\mathrm{CV}_{\text {type }}$, $\mathrm{EH}_{\text {type }}, \mathrm{CI}_{\mathrm{type}}$, and comet $\mathrm{type}_{\text {. }}$ As a proxy of Mars's composition, we take the Bulk-Silicates-Mars (BSM) from Visscher \& Fegley (2013). Compositions for the EH, CV, and CI chondrites are taken from Wasson \& Kallemeyn (1988). Elemental composition for the comet is taken from Huebner \& Boice (1997). Table 1 shows the elemental distribution for all considered impactors. To help understand the differences between the impactors, we also report several elemental ratios such as the $\mathrm{Mg} / \mathrm{Si}, \mathrm{Fe} / \mathrm{O}$, and $\mathrm{C} / \mathrm{O}$ ratios; these play an important role in determining the resulting chemical composition of a mixture. This will be discussed in Section 4.

We also report values from the Sun's photosphere ${ }^{8}$ as reference (Asplund et al. 2009). Note the $\mathrm{H} / \mathrm{O}$ ratio of the solar nebula (Sun) and the abundances of other elements relatives to $\mathrm{O}$ and $\mathrm{C}$. Looking at table 1, we can already notice that we will deal with widely different environments. Moreover, the relative abundances between elements clearly indicate that our systems will return chemical distributions that are far from that one predicted for a solar composition.

The 13 elements considered in Table 1 can form $\sim 6800$ possible compounds, including complex organics, gases, and solids (and excluding liquids). Most of these compounds are not stable at our chosen $T$ and $P$. We derive our fiducial list of compounds starting from that reported in Visscher \& Fegley (2013) and the set of compounds in Pignatale et al. (2011). Complex organics have been excluded from calculations, as their chemistry is driven more by kinetics rather than by thermodynamic equilibrium. C-graphite is taken as representative of the main carbon condensates together with $\mathrm{Fe}_{3} \mathrm{C}, \mathrm{Fe}_{2} \mathrm{C}$, and $\mathrm{SiC}$. Calcium and aluminum refractory species, all main oxides, and main silicates ( $\mathrm{Mg}$ and $\mathrm{Fe}$ silicates) have been taken into account. Sulfides are included as well as water vapor and water ice. We report the complete list of considered species in Table 2. The following nomenclature will be used: olivine (forsterite, $\mathrm{Mg}_{2} \mathrm{SiO}_{4}$, and fayalite, $\mathrm{Fe}_{2} \mathrm{SiO}_{4}$ ), pyroxene (enstatite, $\mathrm{MgSiO}_{3}$, and ferrosilite, $\mathrm{FeSiO}_{3}$ ), plagioclase (anorthite, $\mathrm{CaAl}_{2} \mathrm{Si}_{2} \mathrm{O}_{8}$ and albite, $\mathrm{NaAlSi}_{3} \mathrm{O}_{8}$ ), melilite (gehlenite, $\mathrm{Ca}_{2} \mathrm{Al}_{2} \mathrm{SiO}_{7}$, and akermanite, $\mathrm{Ca}_{2} \mathrm{MgSi}_{2} \mathrm{O}_{7}$ ), fassaite (CaTschermak, $\mathrm{CaAl}_{2} \mathrm{SiO}_{6}$, and diopside, $\mathrm{CaMgSi}_{2} \mathrm{O}_{6}$ ), spinel

\footnotetext{
8 We take the elemental abundances from Asplund et al. (2009) for the given set of elements. Please note that $\mathrm{He}$ is not included in the system and, as a consequence, the abundance of $\mathrm{H}$ raises to $\sim 99 \%$ of the total.
} 
Table 2

Complete List of Gas and Dust Species in the Equilibrium Calculations

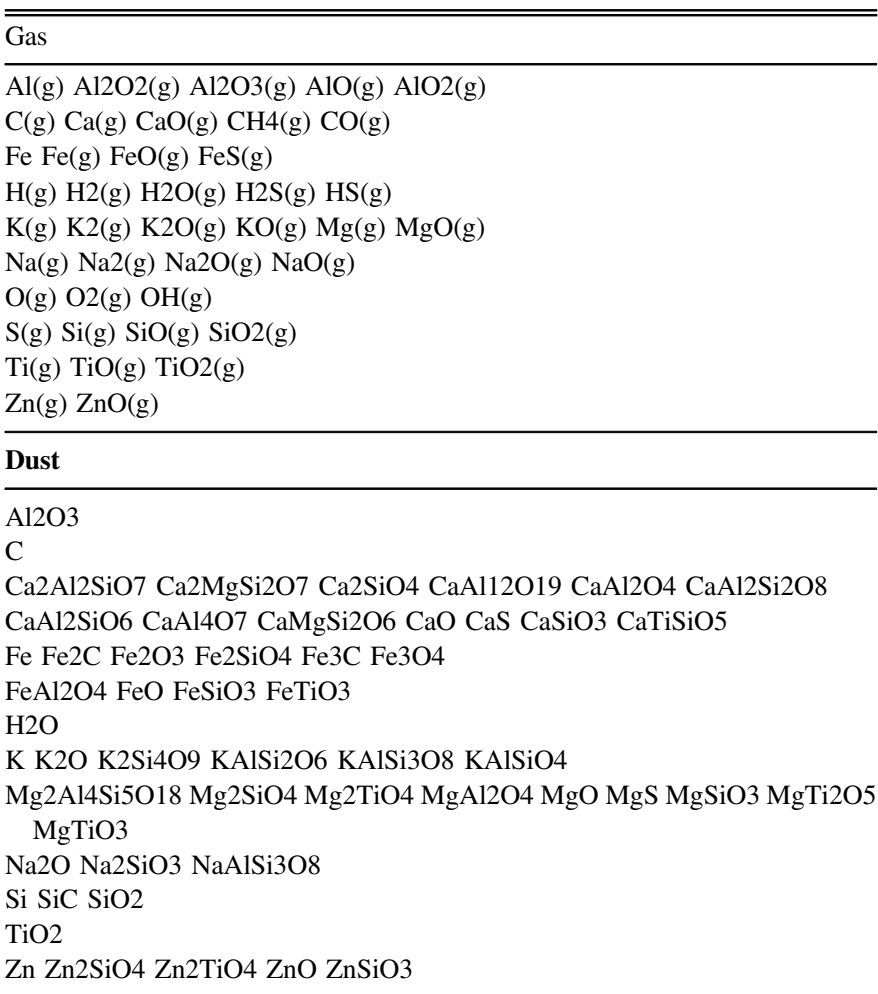

$\left(\mathrm{MgAl}_{2} \mathrm{O}_{4}\right.$ and $\left.\mathrm{FeAl}_{2} \mathrm{O}_{4}\right)$, magnesiowustite $(\mathrm{MgO}$ and $\mathrm{FeO})$, sulfide $(\mathrm{FeS}, \mathrm{MgS}$, and $\mathrm{CaS})$, and metal $(\mathrm{Fe}, \mathrm{Al}$, and $\mathrm{Zn})$. Only the endmembers of each solids solution are considered and no predictions of intermediate compositions are made.

To summarize, we calculate the thermodynamic equilibrium for each of the considered cases in Table 1 at the given temperature $(T=2000 \mathrm{~K})$ and pressure $\left(P=10^{-4}\right.$ bar $)$. The resulting gas phase of Mars plus the gas phase of the selected impactor will constitute the gas mixture from which the dust will condense. The material that is not in the gas phase will form the melt from which the solids will form. To derive the dust composition, we then proceed to the computation of the condensation sequence in the interval of temperatures of $150<T(\mathrm{~K})<2000$ with a constant pressure of $P=10^{-4}$ bar. To derive the solids composition, we compute the CIPW-norm.

To test our thermodynamic model, we also run equilibrium calculation using the solar abundances in Table 1 and compare the results with previous calculations available in the literature. Results of the test and a brief discussion are presented in Appendix A.

\section{Results}

Table 3 shows the elemental abundances ( $\mathrm{mol} \%$ ) of the gas mixture that results from equilibrium calculation at $T=2000 \mathrm{~K}$ and $P=10^{-4}$ bar of Mars plus the considered impactor (Mars+Mars, Mars+CV, Mars+CI, Mars+EH, and Mars+comet). These abundances are used as input to compute the condensation sequence. Table 4 shows the oxides budget of different melt mixtures in case of complete equilibration between Mars and the given impactors. These budgets are used to compute the CIPW-norm.

\subsection{Dust from Condensing Gas}

Figure 2 shows the dust distribution for all the considered impactors in mol\% (being 100 gas+dust) as a function of temperature. From left to right, and from top to bottom, the different cases are ordered with decreasing $\mathrm{Fe} / \mathrm{O}$ ratio of the initial gas mixture (see Table 3).

Mars $+\mathrm{CV}$ impact results in large quantities of metallic iron, $\mathrm{FeS}$ and $\mathrm{SiO}_{2}$. A small amount of pyroxene (enstatite $\left(\mathrm{MgSiO}_{3}\right)$ and ferrosilite $\left.\left(\mathrm{FeSiO}_{3}\right)\right) \sim 1 \mathrm{~mol} \%$, is distributed all along the temperature range. At $T \sim 700 \mathrm{~K}$, we see the appearance of $\mathrm{Fe}_{2} \mathrm{C}$ and $\mathrm{C}$ (graphite). Similar to Mars $+\mathrm{CV}$, the Mars+EH impact shows large quantities of metallic iron, $\mathrm{FeS}$ and $\mathrm{SiO}_{2}$. Moreover, we do see a small percentage of $\mathrm{Si}, \mathrm{MgS}$, and $\mathrm{SiC}$. Traces of pyroxenes are seen at high temperatures only.

The Mars+Mars impact produces several oxides such as $\mathrm{FeO}$ and $\mathrm{Fe}_{3} \mathrm{O}_{4}$, and metallic iron and volatiles such as $\mathrm{Na}_{2} \mathrm{O}$ and $\mathrm{Na}_{2} \mathrm{SiO}_{3}$. Traces of olivine (forsterite $\left(\mathrm{Mg}_{2} \mathrm{SiO}_{4}\right)$ and fayalite $\left.\left(\mathrm{Fe}_{2} \mathrm{SiO}_{4}\right)\right)$ are present at high temperature.

Mars+CI impact returns iron-rich olivine such as fayalite $\left(\mathrm{Fe}_{2} \mathrm{SiO}_{4}\right)$, then $\mathrm{FeO}, \mathrm{Fe}_{3} \mathrm{O}_{4}, \mathrm{Fe}_{2} \mathrm{O}_{3}, \mathrm{FeS}$, and a smaller amount of $\mathrm{SiO}_{2}$. At lower temperature, we see the condensation of $\mathrm{C}$ and $\mathrm{H}_{2} \mathrm{O}$. The dust from Mars+comet impact is mainly made of pyroxene, $\mathrm{SiO}_{2}$ and $\mathrm{FeS}$. Mars+comet impact is that one that produces, as expected, a large amount of water ice together with solid carbon.

Figure 3 shows the condensation sequence for the more volatiles species. All the considered cases return a very similar behavior, as these volatiles are less effected by the changes of other elemental ratios. $\mathrm{Na}(\mathrm{g})$ has higher condensation temperature than $\mathrm{K}(\mathrm{g})$, and $\mathrm{Z}(\mathrm{g})$ is the last one to condense. $\mathrm{Na}_{2} \mathrm{SiO}_{3}$, $\mathrm{K}_{2} \mathrm{Si}_{4} \mathrm{O}_{9}$, and $\mathrm{Zn}_{2} \mathrm{SiO}_{4}$ are the main respective condensates, together with $\mathrm{Zn}$ in case of Mars $+\mathrm{CV}$, Mars $+\mathrm{EH}$, and $\mathrm{Zn}$ and $\mathrm{K}$ for Mars+Mars.

\subsection{Solids from Cooling Melts}

Table 5 reports the resulting CIPW-norm if complete equilibration between the melt belonging to Mars and to the impactor occurs (see Table 4). To establish the reliability of our CIPW-algorithm, we performed calculation using the BSM and compare our result with that of Ronnet et al. (2016), finding a very good agreement (see the last two columns in Table 5).

The resulting solids will generally be characterized by pyroxene ${ }^{9}$ and olivine, with the former in larger abundances, except for the Mars+Mars case for which olivine is slightly more abundant. Although our selected impactors have initially different chemical composition, the resulting CIPW-norm is quite similar for all cases. It is interesting to note that diposide $\left(\mathrm{CaMgSi}_{2} \mathrm{O}_{6}\right)$ is not predicted for a cometary impactor, while corundum $\left(\mathrm{Al}_{2} \mathrm{O}_{3}\right)$ is a tracer of that impact. Enstatite and forsterite will be largely stable and common compounds for all the considered cases. Albite $\left(\mathrm{NaAlSi}_{3} \mathrm{O}_{8}\right)$ and orthoclase $\left(\mathrm{KAlSi}_{3} \mathrm{O}_{8}\right)$ are not present in the solids, because $\mathrm{Na}$ and $\mathrm{K}$ are totally vaporized after the impact (see Tables 3 and 4).

\section{Discussion}

\subsection{Dust Composition}

Our calculations clearly show different behavior when compared with the classical condensation sequence with a

\footnotetext{
9 Hypersthene in Ronnet et al. (2016).
} 
Table 3

Elemental Abundances (mol\%) of the Gas Mixture that Is Released after the Impact, Assuming $T=2000 \mathrm{~K}, P=10^{-4}$ bar, Different Types of Impactors, and Equal Contribution between Mars and the Considered Impactor

\begin{tabular}{|c|c|c|c|c|c|}
\hline Gas Mixture & + Mars & $+\mathrm{CV}$ & $+\mathrm{CI}$ & $+\mathrm{EH}$ & + Comet \\
\hline Element & \multicolumn{4}{|c|}{ Abundances $(\mathrm{mol} \%)$} & \\
\hline $\mathrm{Al}$ & $8.059 \mathrm{E}-06$ & $1.382 \mathrm{E}-05$ & $5.058 \mathrm{E}-06$ & $2.336 \mathrm{E}-05$ & $1.412 \mathrm{E}-05$ \\
\hline $\mathrm{C}$ & $0.000 \mathrm{E}+00$ & $3.762 \mathrm{E}+00$ & $5.791 \mathrm{E}+00$ & $2.060 \mathrm{E}+00$ & $1.141 \mathrm{E}+01$ \\
\hline $\mathrm{Ca}$ & $2.348 \mathrm{E}-05$ & $4.508 \mathrm{E}-05$ & $9.962 \mathrm{E}-06$ & $8.897 \mathrm{E}-05$ & $1.804 \mathrm{E}-04$ \\
\hline $\mathrm{Fe}$ & $1.974 \mathrm{E}+01$ & $2.972 \mathrm{E}+01$ & $6.652 \mathrm{E}+00$ & $3.117 \mathrm{E}+01$ & $8.041 \mathrm{E}-01$ \\
\hline $\mathrm{H}$ & $0.000 \mathrm{E}+00$ & $2.241 \mathrm{E}+01$ & $4.314 \mathrm{E}+01$ & $0.000 \mathrm{E}+00$ & $5.481 \mathrm{E}+01$ \\
\hline K & $3.360 \mathrm{E}+00$ & $2.489 \mathrm{E}-01$ & $1.008 \mathrm{E}-01$ & $2.423 \mathrm{E}-01$ & 4.808E-02 \\
\hline $\mathrm{Mg}$ & $3.539 \mathrm{E}-01$ & $4.512 \mathrm{E}-01$ & $1.000 \mathrm{E}-01$ & $8.458 \mathrm{E}-01$ & $9.982 \mathrm{E}-01$ \\
\hline $\mathrm{Na}$ & $4.905 \mathrm{E}+01$ & $3.859 \mathrm{E}+00$ & $1.502 \mathrm{E}+00$ & $3.543 \mathrm{E}+00$ & $8.026 \mathrm{E}-01$ \\
\hline $\mathrm{O}$ & $2.608 \mathrm{E}+01$ & $2.501 \mathrm{E}+01$ & $3.695 \mathrm{E}+01$ & $2.775 \mathrm{E}+01$ & $2.858 \mathrm{E}+01$ \\
\hline S & $0.000 \mathrm{E}+00$ & $5.519 \mathrm{E}+00$ & $4.000 \mathrm{E}+00$ & $1.120 \mathrm{E}+01$ & $7.121 \mathrm{E}-01$ \\
\hline $\mathrm{Si}$ & $1.146 \mathrm{E}+00$ & $8.663 \mathrm{E}+00$ & $1.735 \mathrm{E}+00$ & $2.310 \mathrm{E}+01$ & $1.825 \mathrm{E}+00$ \\
\hline $\mathrm{Ti}$ & $2.663 \mathrm{E}-01$ & $3.370 \mathrm{E}-01$ & $2.347 \mathrm{E}-02$ & $6.733 \mathrm{E}-02$ & $3.844 \mathrm{E}-03$ \\
\hline $\mathrm{Zn}$ & $1.051 \mathrm{E}-02$ & $1.505 \mathrm{E}-02$ & $1.158 \mathrm{E}-02$ & $2.398 \mathrm{E}-02$ & $2.007 \mathrm{E}-04$ \\
\hline $\mathrm{Mg} / \mathrm{Si}$ & 0.31 & 0.05 & 0.06 & 0.04 & 0.55 \\
\hline $\mathrm{Fe} / \mathrm{O}$ & 0.76 & 1.19 & 0.18 & 1.12 & 0.03 \\
\hline $\mathrm{Fe} / \mathrm{Si}$ & 17.23 & 3.43 & 3.83 & 1.35 & 0.44 \\
\hline$(\mathrm{Fe}+\mathrm{Si}) / \mathrm{O}$ & 0.80 & 1.53 & 0.23 & 1.96 & 0.09 \\
\hline $\mathrm{C} / \mathrm{O}$ & 0.00 & 0.15 & 0.16 & 0.07 & 0.40 \\
\hline $\mathrm{H} / \mathrm{O}$ & 0.00 & 0.90 & 1.17 & 0.00 & 1.92 \\
\hline
\end{tabular}

Table 4

Oxide Composition (wt\%) of the Melt that Results after the Impact, Assuming $T=2000 \mathrm{~K}, P=10^{-4}$ bar, and Different Types of Impactor

\begin{tabular}{lrrrrr}
\hline \hline & + Mars & + CV & + CI & + EH & + Comet \\
\hline $\mathrm{Al}_{2} \mathrm{O}_{3}$ & 2.96 & 3.55 & 3.06 & 3.02 & 3.10 \\
$\mathrm{CO}_{2}$ & 0.00 & 0.00 & 0.00 & 0.00 & 0.00 \\
$\mathrm{CaO}$ & 2.40 & 2.87 & 2.47 & 2.41 & 0.28 \\
$\mathrm{FeO}$ & 17.16 & 12.55 & 14.42 & 12.35 & 17.06 \\
$\mathrm{H}_{2} \mathrm{O}$ & 0.00 & 0.00 & 0.00 & 0.00 & 0.00 \\
$\mathrm{~K}_{2} \mathrm{O}$ & 0.00 & 0.00 & 0.00 & 0.00 & 0.00 \\
$\mathrm{MgO}$ & 30.60 & 30.88 & 31.15 & 32.04 & 31.09 \\
$\mathrm{Na}_{2} \mathrm{O}$ & 0.00 & 0.00 & 0.00 & 0.00 & 0.00 \\
$\mathrm{SiO}_{2}$ & 46.75 & 49.35 & 48.80 & 50.10 & 45.11 \\
$\mathrm{TiO}_{2}$ & 0.13 & 0.80 & 0.10 & 0.09 & 3.37 \\
$\mathrm{ZnO}_{\mathrm{SO}_{3}}$ & 0.00 & 0.00 & 0.00 & 0.00 & 0.00 \\
\hline $\mathrm{Mg} / \mathrm{Si}$ & 0.00 & 0.00 & 0.00 & 0.00 & 0.00 \\
$\mathrm{Fe} / \mathrm{O}$ & 0.98 & 0.93 & 0.95 & 0.95 & 1.03 \\
\hline
\end{tabular}

Note. Total equilibration between mars and impactor is also assumed. The $\mathrm{Mg} / \mathrm{Si}$ and $\mathrm{Fe} / \mathrm{O}$ ratios are the elemental mole ratios.

solar composition (see Figure 5). One of the main reasons is the amount of $\mathrm{H}, \mathrm{C}$, and $\mathrm{O}$ in our systems that is very different from the solar values. Moreover, in our calculations, the amount of $\mathrm{Fe}, \mathrm{Mg}$, and $\mathrm{Si}$ is of the same order of magnitude as $\mathrm{O}$. This is not the case for the solar nebula where $\mathrm{H}$ is predominant, $\mathrm{C}$ is comparable with $\mathrm{O}$, and $\mathrm{Fe}, \mathrm{Mg}, \mathrm{Si}$ are orders of magnitude smaller than O (Asplund et al. 2009). Here, we try to qualitatively understand our results and emphasize the differences from the well-known condensation sequence of the solar nebula.

The stability of forsterite $\left(\mathrm{Mg}_{2} \mathrm{SiO}_{4}\right)$ and enstatite $\left(\mathrm{MgSiO}_{3}\right)$ is driven by the $\mathrm{Mg} / \mathrm{Si}$ ratio, where higher $\mathrm{Mg} / \mathrm{Si}$ ratios $(>1)$ favor forsterite, while lower $\mathrm{Mg} / \mathrm{Si}$ ratios $(<1)$ favor enstatite (Ferrarotti \& Gail 2001). However, at very high temperatures, forsterite can still be the first magnesium silicates that condenses out before being being converted in enstatite (Ferrarotti \& Gail 2001). From Table 3, we see that the Mg/ $\mathrm{Si}$ is well below 1 in all cases, and as expected, the dust is generally enstatite-rich (see Figure 2). The excess of Si that is not consumed in the magnesio-silicates will then be bound with $\mathrm{O}$ to form stable $\mathrm{SiO}_{2}$. Generally $\mathrm{SiO}_{2}$ tends to be more stable than iron oxides (see, for example, ellingham diagrams in DeHoff 1993). Fe and $\mathrm{SiO}_{2}$ can then react to form iron-rich silicates. If oxygen is still available for reaction, it will start to bind iron to form iron oxides. If there is lack of oxygen, iron will be mainly in the metallic form. The presence of sulfur further modifies the expected composition as sulfidation of $\mathrm{Fe}$ occurs.

As a consequence, looking at the elemental ratios reported in Table 3, the behaviors found in Figure 2 become clearer. Let us consider the two extreme cases of the $\mathrm{Fe} / \mathrm{O}$ ratio, Mars + comet $(\mathrm{Fe} / \mathrm{O}=0.03)$, and $\mathrm{Mars}+\mathrm{CV}(\mathrm{Fe} / \mathrm{O}=1.19)$. In the case of Mars+comet, we have $\mathrm{Mg} / \mathrm{Si}=0.55$. As such, we expect the oxygen to form mainly enstatite $\mathrm{MgSiO}_{3}$. Then, we expect the appearance of $\mathrm{SiO}_{2}$, as there is $\mathrm{Si}$ in excess with $\mathrm{Si}$ more abundant than $\mathrm{Fe}(\mathrm{Fe} / \mathrm{Si}=0.44)$. As $\mathrm{Fe} / \mathrm{O}=0.03$ and $(\mathrm{Fe}+\mathrm{Si}) / \mathrm{O}=0.09$, there is a large reservoir of oxygen to oxidize the iron which, indeed, is found in ferrosilite $\mathrm{FeSiO}_{3}$.

On the other hand, let us focus to the Mars+CV case. Here, the small amount of $\mathrm{Mg}$ will form magnesium silicates, and then the excess of $\mathrm{Si}$ will form $\mathrm{SiO}_{2}$ and $\mathrm{FeSiO}_{3}$. The $\mathrm{Fe} /$ $\mathrm{Si}=3.43$ tells us that there is iron in excess compared with $\mathrm{Si}$. The $\mathrm{Fe} / \mathrm{O}=1.19$ and $(\mathrm{Fe}+\mathrm{Si}) / \mathrm{O}=1.53$ also tells us that there is not enough oxygen available to oxidize all of the iron. As a consequence, we expect to see a certain amount of iron to be stable in its metallic form, and FeS given the presence of sulfur in the mixture. Sulfur is also present in the case for Mars $+\mathrm{EH}$, Mars +CI, and Mars+Comet. If a large amount of sulfur is available, as in the the Mars $+\mathrm{EH}$ impact, $\mathrm{MgS}$ also becomes a stable sulfide. 

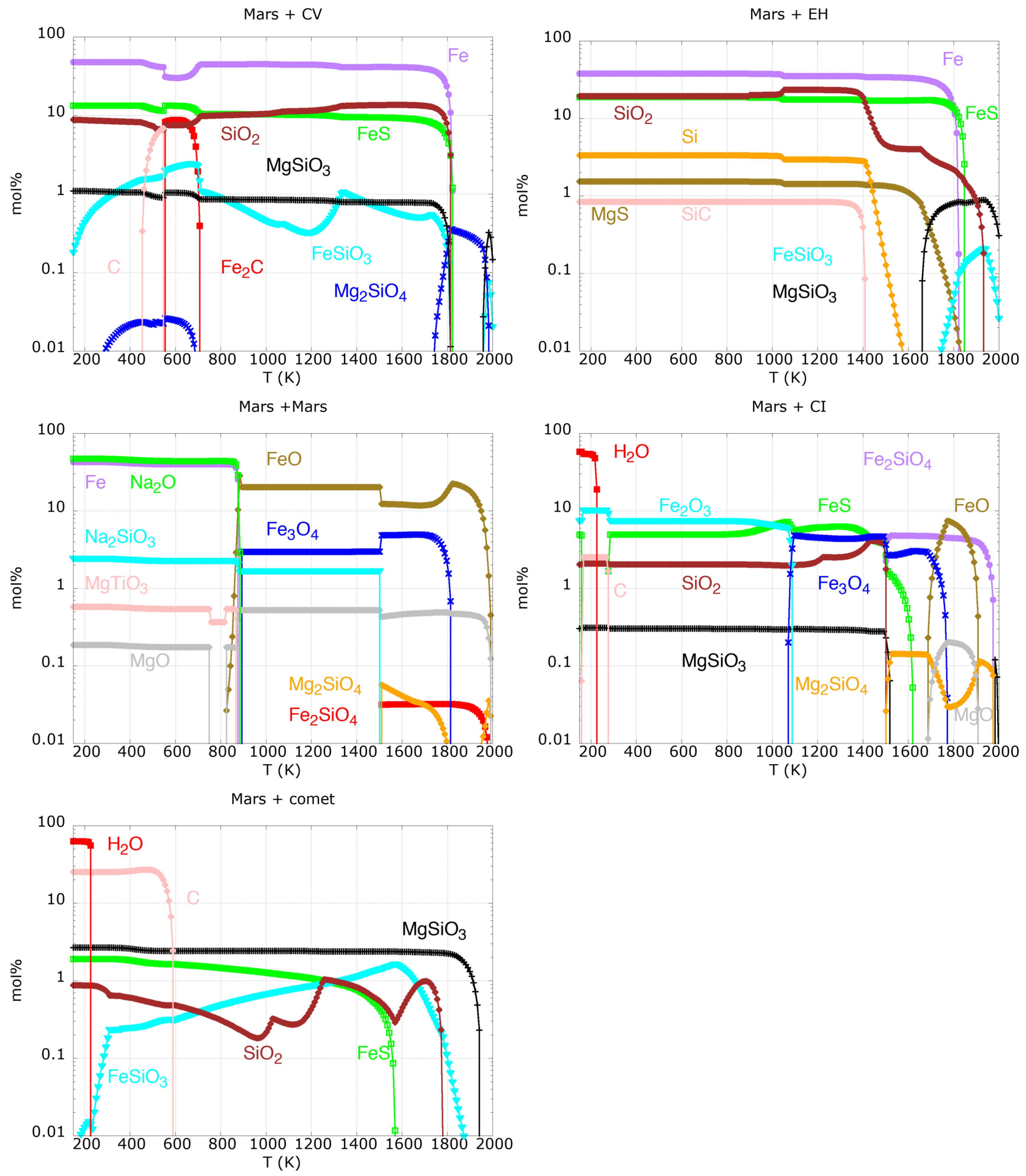

Figure 2. Condensation sequences for major dust species (mol\%) that result from the gas mixtures in Table 3. Note the changes of colors when different compounds are considered.

Interesting cases are also the Mars+Mars and Mars+CI. $\mathrm{Here}$, the high $\mathrm{Fe} / \mathrm{Si}$ ratios but low $\mathrm{Fe} / \mathrm{O}$ ratios return a large amount of several iron oxides; there is not enough $\mathrm{Si}$ to form large amounts of iron-silicates, thus the $\mathrm{O}$ binds directly the iron in several iron oxides. The Mars+EH impact clearly shows the effect of the sulfide-rich impactor, given the presence of $\mathrm{MgS}$ together with FeS.
Our calculations show that different impactors result in dust with traceable different compositions. This opens the possibility to identify the individual composition of the impactor from the determination of the dust composition of Phobos and from the samples collected by the MMX mission.

In conclusion, dust from different bodies will be characterized by different (i) degrees of iron-oxidation; (ii) the 

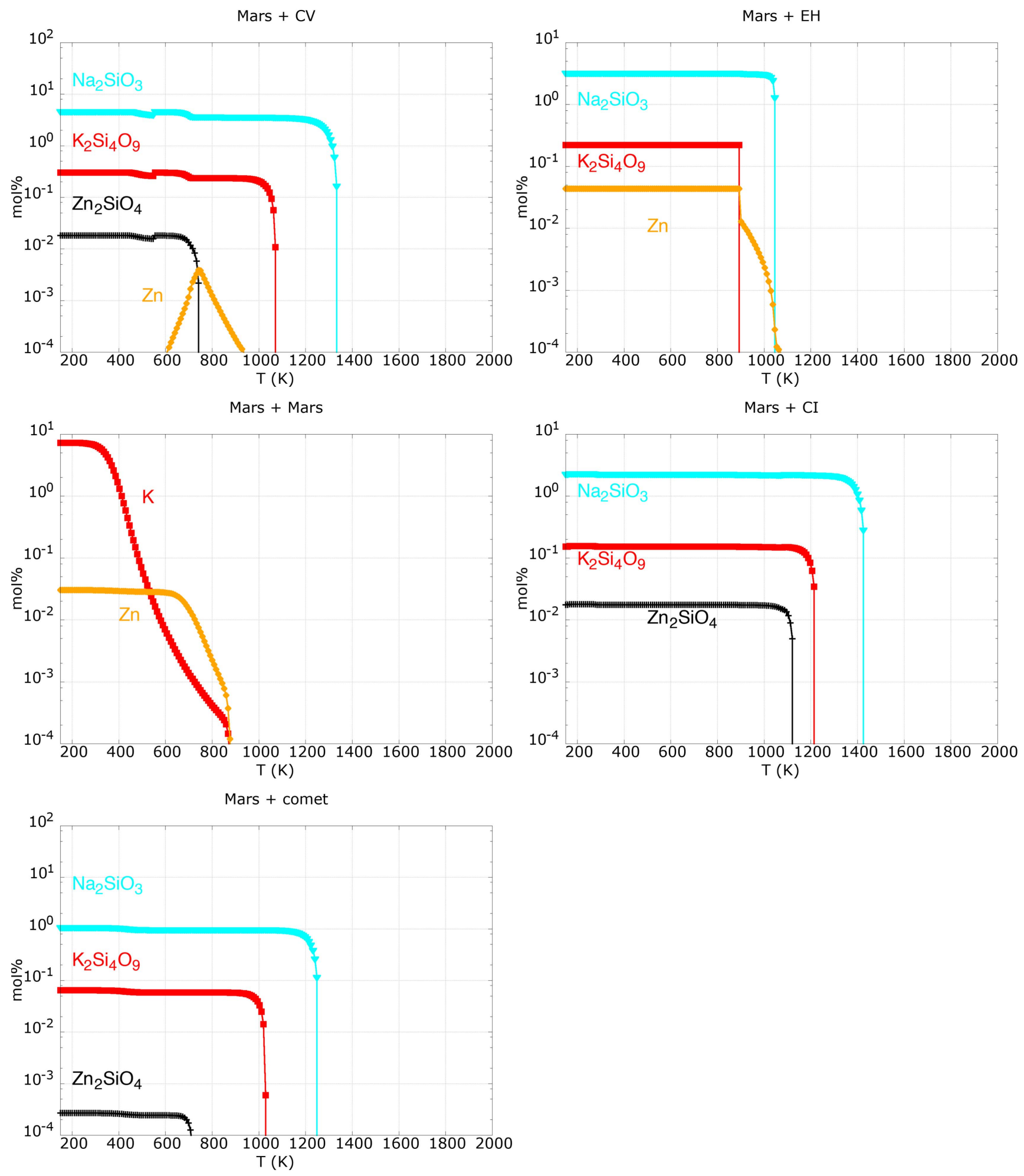

Figure 3. Condensation sequences for $\mathrm{K}, \mathrm{Zn}$, and $\mathrm{Na}$ compounds (mol\%) that result from the gas mixtures in Table 3. Sodium compounds for Mars+Mars were included in Figure 2 as, in that case they represent major species. Note the changes of scales in the $y$-axis.

presence of iron-silicates and/or iron oxides; (iii) the amount of sulfides; and (iv) the amount of carbon and ice. All of the condensation sequences return a generally poor content of olivine and pyroxene, with a preference of the latter. A qualitative analysis of different elemental ratios can then be useful to derive the chemistry of impactors that are not considered in this work.

\subsubsection{Carbon, Water Ice, and Other Volatiles}

In our calculations, we see the appearance of solid $\mathrm{C}$ in the cases of Mars $+\mathrm{CV}$, Mars $+\mathrm{CI}$, and Mars + comet, while $\mathrm{SiC}$ is the most stable C-bearing compound in the case of Mars+EH. Mars $+\mathrm{CV}$, Mars+CI, and Mars+comet have carbon and hydrogen in the gas mixture, while in the Mars+EH case, there is carbon only. 
Table 5

Resulting CIPW-norm of the Melt Phase

\begin{tabular}{|c|c|c|c|c|c|c|c|}
\hline & + Mars & $+\mathrm{CV}$ & $+\mathrm{EH}$ & $+\mathrm{CI}$ & + COMET & BSM & BSM (Ronnet et al. 2016) \\
\hline Anorthite & 8.08 & 9.69 & 8.24 & 8.35 & 1.39 & 3.16 & \\
\hline Diopside & 3.08 & 3.63 & 2.97 & 3.13 & 0.00 & 6.89 & 6.97 \\
\hline Pyroxene & 43.41 & 55.48 & 57.58 & 52.35 & 54.97 & 21.03 & 21.29 \\
\hline Orthoclase & 0.00 & 0.00 & 0.00 & 0.00 & 0.00 & 0.65 & 0.66 \\
\hline Olivine & 45.19 & 29.68 & 31.05 & 35.98 & 34.66 & 58.50 & 59.22 \\
\hline Ilmenite & 0.25 & 1.52 & 0.17 & 0.19 & 6.40 & 0.27 & 0.00 \\
\hline $\mathrm{Oli} / \mathrm{Pyr}$ & 1.04 & 0.53 & 0.62 & 0.68 & 0.63 & 2.78 & 2.78 \\
\hline
\end{tabular}

Note. Calculations for the BSM are also performed to compare the resulting CIWP-norm with values derived by Ronnet et al. (2016).

The carbon-to-oxygen ratio $(\mathrm{C} / \mathrm{O})$ is an important parameter that determines the presence of solid carbon, water vapor, and other oxides. At high temperature, $\mathrm{CO}(\mathrm{g})$ will consume all of the $\mathrm{C}$ available before allowing the formation of water vapor (Larimer 1975). This has strong implications in the formation of complex organics and water (if hydrogen is present in the system).

The chemistry of carbon cannot be totally determined by thermodynamic equilibrium. The behavior of $\mathrm{CO}(\mathrm{g})$ in a $\mathrm{H}_{2} \mathrm{O}(\mathrm{g})-\mathrm{H}_{2}(\mathrm{~g})$ gas in the temperature range of $100<T(\mathrm{~K})<$ $700 \mathrm{~K}$ is ruled by kinetics and the environmental condition. The classical transition around $T \sim 700 \mathrm{~K}$ where $\mathrm{CO}(\mathrm{g})$ is transformed in $\mathrm{CH}_{4}$ can be described, for example, by a reaction of the type $n \mathrm{CO}+(1+2 n) \mathrm{H}_{2} \rightleftharpoons \mathrm{C}_{\mathrm{n}} \mathrm{H}_{2 \mathrm{n}+2}+\mathrm{nH}_{2} \mathrm{O}$. This is shown in Figure 5 (right panel) where $n=1$ and the reaction is $\mathrm{CO}(g)+3 \mathrm{H}_{2}(g) \rightleftharpoons \mathrm{CH}_{4}(g)+\mathrm{H}_{2} \mathrm{O}(g)$.

In fact, this reaction is just a first simplified transcription of the many Fischer-Tropsh-like reactions that can occur in this temperature range and at different $\mathrm{H}_{2} / \mathrm{CO}$ ratios (Sekine et al. 2006; Nuth et al. 2008). Fischer-Tropsh processes produce complex organics on the surface of dusty grains in the presence of the right catalyst. There are different catalysts with their own properties, but usually in astrophysics context, the iron-based Fischer-Tropsh is the most considered because of the abundances of this element in the solar nebula (Fegley 1988; Asplund et al. 2009).

There are numerous competitive reactions that determine the rate and the production of organics (Fegley 1988) and several theoretical models have been largely described in material science (see, for example, Zimmerman \& Bukur 1990). However, the resulting amount of organics is extremely difficult to calculate theoretically when an astrophysical environment is considered. This comes from the large uncertainty in determining, for example, the amount and the surface of catalyst available.

Nevertheless, the possible pathways to the formation of carbon-rich material are vastly more numerous. In our Mars+comet case, for example, the reaction $\mathrm{CO}(g)+$ $\mathrm{H}_{2}(g) \rightleftharpoons \mathrm{C}+\mathrm{H}_{2} \mathrm{O}(g)$ becomes active as well. This is clearly seen in Figure 4, where $\mathrm{H}_{2}(\mathrm{~g})$ and $\mathrm{COg}$ are depleting as $\mathrm{CH}_{4}(\mathrm{~g}), \mathrm{H}_{2} \mathrm{O}(\mathrm{g})$, and $\mathrm{C}$ become more stable. In this work, we do not perform any kinetics calculation and because we have only a few carbon-solids in our list, we can only suggest that the presence of $\mathrm{C}$ and $\mathrm{H}$ in Mars+CI, Mars+Comet and Mars $+\mathrm{CV}$ impacts can produce complex organics and carbonenriched dust. The case of Mars $+\mathrm{CV}$ is then extremely

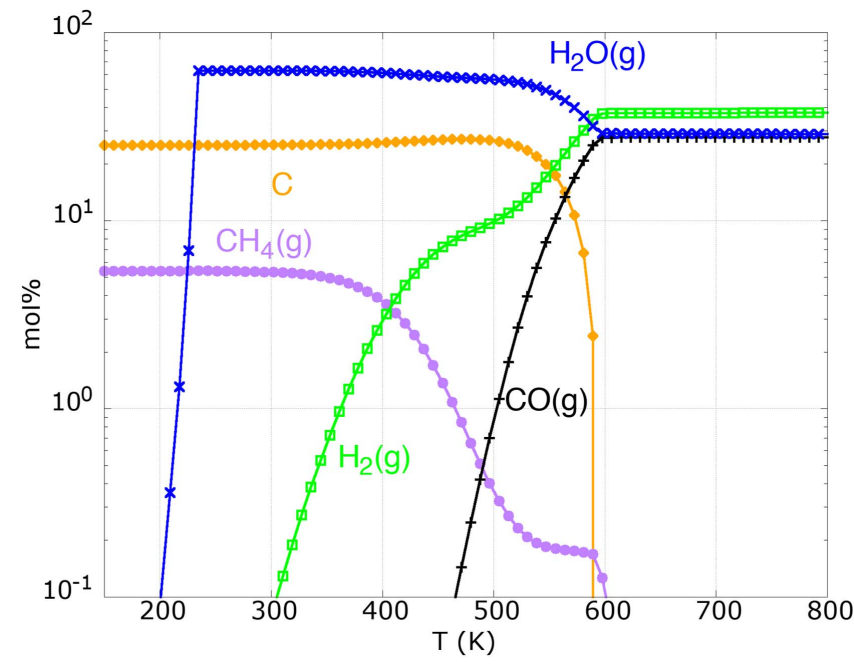

Figure 4. Thermodynamic calculations in the + comet case shows a possible pathway for the condensation of graphite. In fact, together with the well-known transformation of $\mathrm{CO}(\mathrm{g})$ in $\mathrm{CH}_{4}(\mathrm{~g})\left(\mathrm{CO}(g)+3 \mathrm{H}_{2}(g) \rightleftharpoons \mathrm{CH}_{4}(g)+\mathrm{H}_{2} \mathrm{O}(g)\right)$, we do see the reaction $\mathrm{CO}(g)+\mathrm{H}_{2}(g) \rightleftharpoons \mathrm{C}+\mathrm{H}_{2} \mathrm{O}(g)$ that occurs at temperature lower than $\mathrm{T}=600 \mathrm{~K}$.

interesting, because there may be enough metallic iron, together with carbon, to enhance the production of complex organics.

Equilibrium calculations return an efficient evaporation of the carbon-rich dust present in the impactor. However, the rate of vaporization will be driven by the physical and chemical properties of the carbon species. For example, carbon-rich insoluble organic material (IOM), if present, could survive the impact, as it is refractory (Pizzarello et al. 2006). This could reduce the amount of carbon released in the gas phase. Nevertheless, the presence of carbon in the MMX samples in the form of new condensates and/or in IOM will still be tracer of the nature of the impactor.

In Section 3, we pointed out that the gas mixture is volatileenriched. Figure 3 shows that $\mathrm{K}-, \mathrm{Na}-$, and $\mathrm{Zn}$-silicates are stable as the temperature drops. Mono atomic $\mathrm{Zn}$ is also predicted for the Mars+EH and Mars+Mars case. There are no dramatic differences between the considered impactors when $\mathrm{K}, \mathrm{Na}$, and $\mathrm{Zn}$ are taken into account.

In conclusion, the condensing dust will be volatile (and in some cases, also carbon) enriched compared to the solids that result from the cooling melts. The presence of volatile-rich dust in MMX samples thus indicates that vaporization followed by condensation had occurred and no volatiles left the system. 
Moreover, as $\mathrm{Na}, \mathrm{K}$, and $\mathrm{Zn}$ condense at different temperature, their presence or absence could return information on the temperature at which aggregation of a given sample occurred.

Mars +CI and Mars+comet are the only cases for which, at low temperature, we see condensation of water vapor into ice. The presence of ice will favor secondary alteration of the dust allowing, for example, the formation of phyllosilicates (Bischoff 1998).

\subsection{Solids Composition}

In Table 5, we reported the resulting CIPW-norm of the solids if complete equilibration between Mars and impactor occurred. The composition of the solids generally comprises olivine (forsterite and fayalite) and pyroxene (enstatite and ferrosilite). Ronnet et al. (2016) calculated the CIPW normative mineralogy for Mars-, moon-, and IDP-like impactors. They found that the resulting composition of a Mars-like impactor would be olivine and pyroxene rich. In particular, their CIPW-norm for Mars is characterized by high olivine content (olivine/pyroxene $>1$ ).

Our results for the Mars+Mars case show that the solids (deprived of all the vaporized material) will have an olivine/ pyroxene $\sim 1$, whereas the other cases return a olivine/ pyroxene $<1$.

There are no dramatic differences between the solids that results from different impactors (except for the aforementioned corundum in the comet case). It is interesting to note that solids that result from cooling melts do not show as much as variation in their composition compared to the dust. The resulting composition of solids appears, thus, to contain less information on the origin of the impactor compared with the large quantities of clues that can be derived from condensed dust. Nonetheless, the composition of melts can be affected by different cooling conditions, microgravity, and gas fugacities. Nagashima et al. (2006, 2008) performed laboratory experiments on cooling forsterite and enstatite melts. They found that different cooling rates and microgravity can alter and even suppress crystallization only allowing the formation of glass material. Further experimental investigations are already planned to derive predictions of the composition of the cooling melts.

On the physical point of view, condensates and solids from melts may be distinguished by their different crystalline structure, microporosity, zoning, and interconnections between different phases. Indeed, the resulting physical properties of dust from gas and solids from melts are determined by many factors (Nishinaga 2014). Furthermore Hyodo et al. (2017a) showed that while the size of dust would be in the order of $0.1 \sim 10 \mu \mathrm{m}$, solids from melts can reach $1 \sim 10 \mathrm{~m}$ in size and then they can be grinded down to $\sim 100 \mu \mathrm{m}$. Thus, we could expect to find different size distributions when dust and solids are compared.

\subsection{Infrared Spectra of Phobos}

Giuranna et al. (2011) presented a detailed investigation on the possible composition of the dust and rocks present on the Phobos's surface. They suggested that the "blue" part of Phobos is consistent with phyllosilicates, while the "red" region is compatible with the presence of feldspar. No bulk chondrite compositions are able to reproduce the current observation (Giuranna et al. 2011).

Phyllosilicates are not product of condensation, but derive from secondary alterations of silicates (Bischoff 1998) and, as a consequence, they are not predictable with our calculations, although we do have all the dust (silicates) at the base of their formation. The major feldspar compounds are orthoclase $\left(\mathrm{KAlSi}_{3} \mathrm{O}_{8}\right)$, albite $\left(\mathrm{NaAlSi}_{3} \mathrm{O}_{8}\right)$, and anorthite $\left(\mathrm{CaAl}_{2} \mathrm{Si}_{2} \mathrm{O}_{8}\right)$. Not all of them are compatible with our model, as $\mathrm{Na}$ and $\mathrm{K}$ are separated from $\mathrm{Al}$ after the impact and others are the predicted stable compounds. On the other hand, we do see the formation of anorthite (see Table 5).

Nevertheless, Giuranna et al. (2011) stressed that more fine modeling is needed, as a mixture of different materials made of fine grains could also produce the observed trends. This becomes important as previous modeling focused on the analysis of the spectral properties of "external" objects (such as different types of asteroids) to match the observed spectra, as the capture scenario suggests. The impact-generated scenario imposes to re-think this approach.

Ronnet et al. (2016) analyzed the resulting composition of the melts generated by different impactors to find a match with the observations. They concluded that more than the melt, the gas-to-dust condensation in the outer part of an impactgenerated disk could be able to explain the spectral properties of Phobos and Deimos. This further suggests that our derived dust may play an important part in producing the observed trends. Moreover, as the Hyodo et al. (2017a) disk model shows that the melt would be mixed with the gas, the combined effect of dust and solids should be taken into account.

In this section, we try to predict the effects of our mixed material (dust plus solids) on the infrared spectra. In the introduction, we presented possible mechanisms listed by Giuranna et al. (2011) that could be able to reproduce the observed trend in the VIS-NIR. Here, we recall them and compare them with our following results:

(i) A low percentage of iron-rich olivine and pyroxene can reduce the spectra. Our resulting dust mixtures generally have a very low concentration $(\sim 1 / \mathrm{mol} \%)$ of iron-rich olivine (fayalite, $\mathrm{Fe}_{2} \mathrm{SiO}_{4}$ ) and pyroxene (ferrosilite, $\mathrm{FeSiO}_{3}$ ). Only the high-temperature region of Mars+CI shows a larger amount of fayalite (see Figure 2).

(ii) A mixture of opaque material (metal iron, iron-oxide, and carbon) reduce the emissivity. We do have a metallic iron-rich dust that results from several impactors (Mars $+\mathrm{CV}, \mathrm{Mars}+\mathrm{EH}$, and Mars+Mars only at low temperature). Carbon dust is also seen in our calculations (Mars+CV, Mars $+\mathrm{CI}$, Mars+comet). Moreover, together with $\mathrm{Fe}$, iron sulfide $(\mathrm{FeS})$, that we see in Mars $+\mathrm{CV}$, Mars +EH, Mars $+\mathrm{CI}$, and Mars+comet, is opaque and featureless in the NIR, but may be recognizable in the MIDIR (Wooden 2008; Henning \& Meeus 2011).

(iii) Quenched material lacks of perfect crystalline structure and, thus, reflectance. Solids from the melts, in our final assemblage, can have the characteristics suggested by Giuranna et al. (2011).

(iv) The reflectance of fine grains is reduced. The average size of the condensed dust is in the order of $0.1 \sim 10 \mu \mathrm{m}$ Hyodo et al. (2017a).

Our proposed model of Phobos as a result of accretion of dust from gas condensation and solids from melts, together with our derived chemical composition, looks promising when discussing spectra. Nevertheless, there are some aspects that needs further investigation: (i) it is important, at this point, to derive the MIDIR spectra of our propose mixtures, and then (ii) estimate the effect of space weathering on it and on the 
resulting albedo. These points can be considered as main topics for future works.

\subsection{Limitations}

In this work, we assume thermodynamic equilibrium (where all the reactions rates are much shorter than the disk cooling timescale) and mass conservation. All the material is available for reaction until the equilibrium is reached at any given temperature. This may not always be the case. As dust condenses out from the gas, it can be subject to different drag forces and separate from the current environment. This process can lead to the so called "fractionated" condensation sequence. If this is the case, a given dust grain can become representative of the temperature, pressure, gas mixture, and dust species that were present when its condensation occurred.

Moreover, dust from secondary condensations (from a now fractionated gas) may then form. These fractionated and incomplete condensation sequences have been the subject of several studies (Hutson \& Ruzicka 2000; Blander et al. 2009; Pignatale et al. 2016) that all show that different pathways of condensation can depart from the main line. For example, Pignatale et al. (2016) showed that, starting with a gas of solar composition, a mixture of enstatite-rich and $\mathrm{SiO}_{2}$-rich dust can be produced in case of systematic sharp separation between dust and gas. $\mathrm{SiO}_{2}$ is a condensate that is not predicted ("incompatible") when solar abundances are considered.

In this work, we do not perform fractionated condensation sequences, as the possible pathways are numerous. However, in the same way, the presence of some "incompatible" condensates together with "predictable" dust in the same MMX sample may point to incomplete or secondary condensation.

As mentioned, Hyodo et al. (2017a) demonstrated that there will be likely no complete equilibration between the melts of Mars and the melts of the impactor. What is likely to occur is a wide spectrum with different degrees of equilibration. A random sampling of solids may thus show material that come from Mars, the impactor or several degrees of mixing.

In our calculations we kept the pressure constant and fixed at $P=10^{-4}$ bar as in Hyodo et al. (2017a). In general, lower pressures (in order of magnitude) move the condensation of the dust toward lower temperatures (Yoneda \& Grossman 1995; Gail 1998). In this case, for our given temperature, more material could vaporize and go into the gas phase. Increasing the pressure (in order of magnitude) has the opposite effect as the condensation temperature increases. As a consequence, we could observe different amount of $\mathrm{Fe}, \mathrm{Mg}$, and $\mathrm{Si}$ moving to the gas phase. Changes in disk pressure may also occur if large amounts of volatiles are injected in the system after the impact. This could be the case of the Mars+comet impact, where the release of $\mathrm{H}_{2} \mathrm{O}(\mathrm{g})$ and $\mathrm{CO}(\mathrm{g})$ could change the total pressure in the disk increasing it, or when a water-rich Mars is considered (Hyodo et al. 2017a). Observed deviations from the predicted trends could then be associated to strong variation in the pressure in the Mars's moons-formation region of the disk or, in fact, to a radial gradient of temperature and pressure in the disk. As a reference for future experimental work, we report in Appendix B (see Figure 6) the partial pressures of the major gas component for Mars+CI, Mars+CV, and Mars+comet impacts. These are the impacts that produce the larger amount of gas such as $\mathrm{H}_{2} \mathrm{O}(\mathrm{g})$ and $\mathrm{CO}(\mathrm{g})$. These values can be used to set up the conditions in which experiments can be performed.

\section{Conclusions}

In this work, we used thermodynamic equilibrium calculation to investigate the chemical composition of dust (from condensing gas) and solids (from cooling melt) as the building blocks of Phobos and Deimos in the impact-generated scenario with the thermodynamic conditions of Hyodo et al. (2017a).

We found that dust and solids have different chemical and physical properties. Dust carries more information on the impactor than the solids. Our results show that it would be possible to distinguish from different types of impactors as each case returns several unique tracers in the dust: a Mars $+\mathrm{CV}$ has large quantities of metallic iron, $\mathrm{SiO}_{2}$, iron sulfides and carbon; Mars +Comet has pyroxenes and the largest carbon and ice reservoir. Mars+EH impact has dust with high metallic iron content, $\mathrm{SiO}_{2}$, sulfides ( $\mathrm{FeS}$ and $\mathrm{MgS}$ ) and traces of $\mathrm{SiC}$. Impact with Mars-like objects returns several iron oxides, and the dust in Mars+CI has iron oxides, water ice, and carbon.

The presence or absence of metallic iron, iron-silicates, iron oxides, sulfides, carbon, and water ice can be considered as clues of different impactors. Deviations from the derived compositions can be then ascribed to fractionated condensation sequences and/ or strong variations in the disk pressure and/or impactors with different elemental composition than investigated in this study.

The giant-impact scenario imposes to re-think the dust modeling for the infrared spectra, as Phobos, in this case, would be made of a complex mixture of dust and solids and not of a prebuilt object as the capture scenario suggests. A qualitative analysis suggests that our derived composition of dust and solid can be compatible with the characteristic of the Phobos VIS-NIR spectra.

In conclusion, the proposed scenario of Phobos as the result of accretion of dust and solid in an impact-generated disk can reconcile with both the dynamical and spectral properties of the Mars' moon. Our dust tracers can be then used in the analysis of the samples returned by the JAXA's MMX mission.

The authors thank the anonymous referee for the comments and suggestions that let us investigate our assumptions in more detail, which improved the manuscript. The authors acknowledge the financial support of ANR-15-CE31-0004-1 (ANR CRADLE), INFINITI (INterFaces Interdisciplinaires NumèrIque et ThèorIque), and UnivEarthS Labex program at Sorbonne Paris Cite (ANR-10- LABX-0023 and ANR-11IDEX-0005-02). P.R. has been financially supported for his preliminary contribution to this work by the Belgian PRODEX programme, managed by the European Space Agency in collaboration with the Belgian Federal Science Policy Office. S.C., R.H., and H.G. acknowledge the financial support of the JSPS-MAEDI bilateral joint research project (SAKURA program). H.G. also acknowledges JSPS KAKENHI grant Nos. JP17H02990 and JP17H06457, and thanks the Astrobiolgy Center of the National Institutes of Natural Sciences (NINS).

\section{Appendix A Solar Condensation Sequence}

Condensation sequences calculated with solar abundances are very distinctive and characterized by smooth transitions between refractories, main silicates, and metallic iron and lowtemperature material (such as sulfides; Larimer 1979; Yoneda \& Grossman 1995; Lodders 2003; Pignatale et al. 2011). 

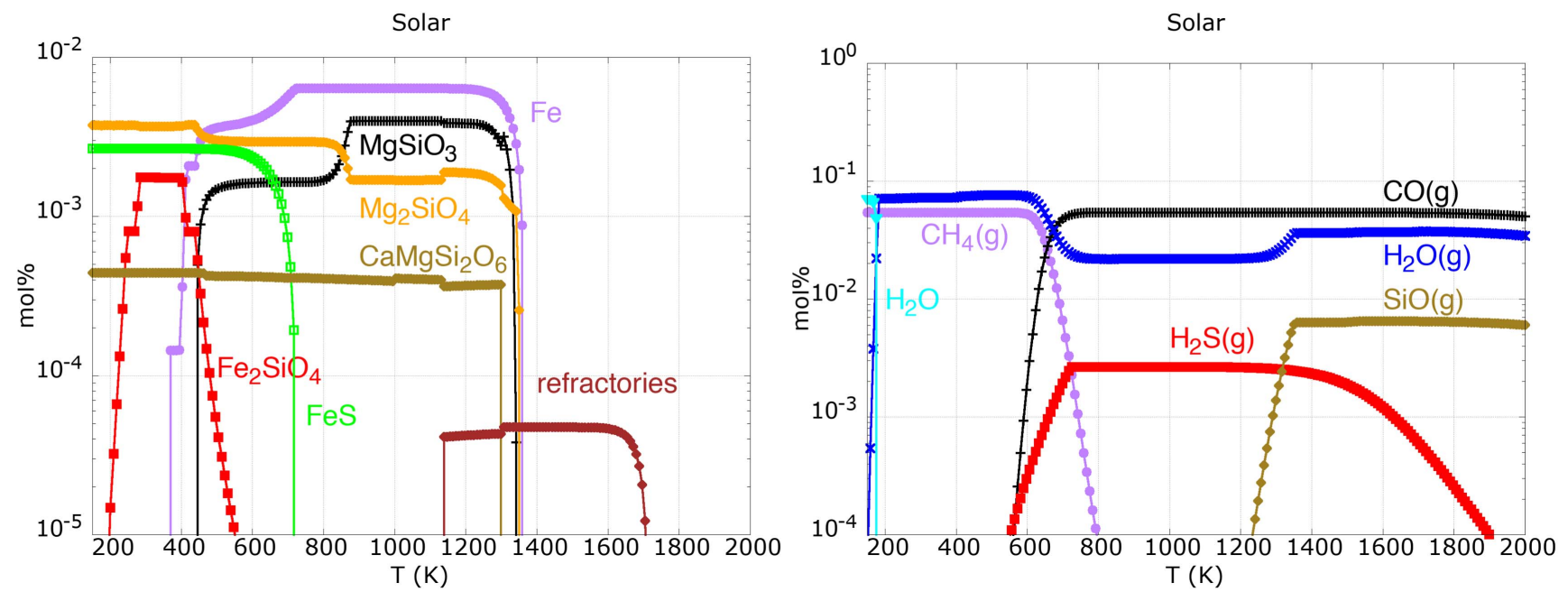

Figure 5. Condensation sequence for major solids (left) and gas (right) starting with an initial gas with solar composition. There is a very good agreement between these results and those reported in Pignatale et al. (2011) and references therein.
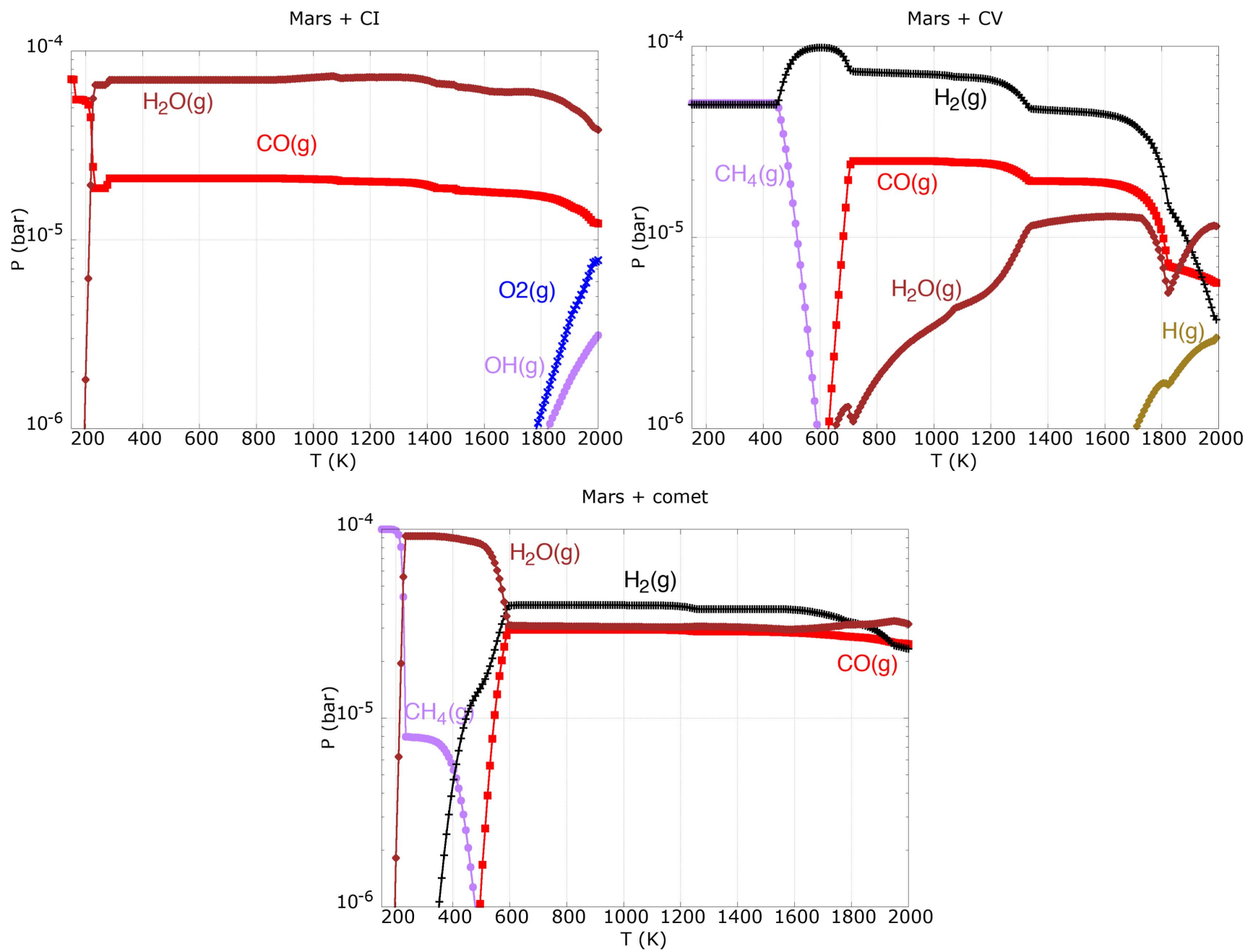

Figure 6. Partial pressure for major gas in the Mars $+\mathrm{CI}$, Mars $+\mathrm{CV}$, and Mars + comet impacts. The total pressure of the system is $P=10^{-4}$ bar.

Figure 5 reports the condensation sequence calculated with our thermodynamic system and the solar abundances listed in Table 1 in the temperature range of $150<T(\mathrm{~K})<2000$ and pressure $P=10^{-4}$ bar. The small fraction of solids that are stable at high temperature $(T>1400 \mathrm{~K})$ are the refractories calcium-aluminum silicates, while at $T \sim 1400 \mathrm{~K}$ iron, forsterite and enstatite condense. At lower temperature, we see the formation of troilite $(\mathrm{FeS})$ and fayalite $\left(\mathrm{Fe}_{2} \mathrm{SiO}_{4}\right)$. $\mathrm{CO}(\mathrm{g}), \mathrm{H}_{2} \mathrm{O}(\mathrm{g})$ and $\mathrm{SiO}(\mathrm{g})$ are the main O-binding gaseous species. At $T \sim 700 \mathrm{~K}$, we see the conversion of $\mathrm{CO}(\mathrm{g})$ to $\mathrm{CH}_{4}$, while $\mathrm{H}_{2} \mathrm{~S}$ is the main sulfur-binding gas until the condensation of troilite. 
These results are in very good agreement with previous works (Larimer 1979; Yoneda \& Grossman 1995; Lodders 2003) on the solar condensation sequence and make us confident on our built system.

\section{Appendix B \\ Partial Pressures of main Gaseous Compounds}

In Figure 6, we report the partial pressures for the main gaseous species as they result from our equilibrium calculations. The chosen case are Mars $+\mathrm{CI}$, Mars $+\mathrm{CV}$, and Mars+ comet. These are the impacts that introduce $\mathrm{H}, \mathrm{C}$, and $\mathrm{O}$ in the system. In our calculations, ideal gas are considered. As a consequence, their partial pressure can be taken as a proxy for their fugacity. These values can be used to set the initial gas environment in further experimental studies.

\section{ORCID iDs}

Francesco C. Pignatale (i) https://orcid.org/0000-00030902-7421

Sébastien Charnoz (i) https://orcid.org/0000-0002-7442-491X

\section{References}

Asplund, M., Grevesse, N., Sauval, A. J., \& Scott, P. 2009, A\&ARA, 47, 481 Bischoff, A. 1998, M\&PS, 33, 1113

Blander, M., Pelton, A. D., \& Jung, I.-H. 2009, M\&PS, 44, 531

Bond, J. C., O'Brien, D. P., \& Lauretta, D. S. 2010, ApJ, 715, 1050

Bottke, W. F., \& Andrews-Hanna, J. C. 2017, NatGe, 10, 344

Brasser, R., \& Mojzsis, S. J. 2017, GeoRL, 44, 5978

Brasser, R., Mojzsis, S. J., Matsumura, S., \& Ida, S. 2017, E\&PSL, 468, 85

Burns, R. G. 1993, Mineralogical Applications of Crystal Field Theory, Vol. 5 (Cambridge: Cambridge Univ. Press)

Citron, R. I., Genda, H., \& Ida, S. 2015, Icar, 252, 334

Cloutis, E. A., Gaffey, M. J., Smith, D. G. W., \& Lambert, R. S. J. 1990a, JGR, 95, 8323

Cloutis, E. A., Gaffey, M. J., Smith, D. G. W., \& Lambert, R. S. J. 1990b, JGR, 95,281

Cloutis, E. A., Gaffey, M. J., Smith, D. G. W., \& Lambert, R. S. J. 1990c, Icar, 84, 315

Cloutis, E. A., Smith, D. G. W., Lambert, R. S. J., \& Gaffey, M. J. 1990d, Icar, 86, 383

Craddock, R. A. 2011, Icar, 211, 1150

Cross, W., Iddings, J. P., Pirsson, L. V., \& Washington, H. S. 1902, JG, 10,555

DeHoff, R. 1993, Thermodynamics in Materials Science (New York: McGraw-Hill)

Ebel, D. S., \& Grossman, L. 2001, GeCoA, 65, 469

Ebel, D. S. 2006, in Meteorites and the Early Solar System II, ed. D. S. Lauretta \& H. Y. McSween (Tucson, AZ: Univ. Arizona Press), 253

Fegley, B., Jr. 1988, in Workshop on the Origins of Solar Systems, ed J. A. Nuth \& P. Sylvester (Houston, TX: Lunar and Planetary Institute), 51 Ferrarotti, A. S., \& Gail, H.-P. 2001, A\&A, 371, 133

Gail, H.-P. 1998, A\&A, 332, 1099
Gail, H.-P., \& Sedlmayr, E. 1999, A\&A, 347, 594

Giuranna, M., Roush, T. L., Duxbury, T., et al. 2011, P\&SS, 59, 1308

Henning, T., \& Meeus, G. 2011, in Physical Processes in Circumstellar Disks around Young Stars, ed. P. J. V. Garcia (Chicago, IL: Univ. Chicago Press), 114

Hesselbrock, A. J., \& Minton, D. A. 2017, NatGe, 10, 266

Huebner, W. F., \& Boice, D. C. 1997, in Comets and the Origin and Evolution of Life, ed. P. J. Thomas, C. F. Chyba, \& C. P. McKay (New York: Springer), 111

Hutson, M., \& Ruzicka, A. 2000, M\&PS, 35, 601

Hyodo, R., Genda, H., Charnoz, S., \& Rosenblatt, P. 2017a, ApJ, 845, 125

Hyodo, R., Rosenblatt, P., Genda, H., \& Charnoz, S. 2017b, ApJ, 851, 122

Klima, R. L., Pieters, C. M., \& Dyar, M. D. 2007, M\&PS, 42, 235

Larimer, J. W. 1975, GeCoA, 39, 389

Larimer, J. W. 1979, Icar, 40, 446

Lodders, K. 2003, ApJ, 591, 1220

Lodders, K., \& Fegley, B. 1997, in AIP Conf. Ser. 402, Astrophysical Implications of the Laboratory Study of Presolar Materials, ed. T. J. Bernatowicz \& E. Zinner (Melville, NY: AIP), 391

Madhusudhan, N., Lee, K. K. M., \& Mousis, O. 2012, ApJL, 759, L40

Murchie, S. 1999, JGR, 104, 9069

Murchie, S. L., Britt, D. T., Head, J. W., et al. 1991, JGR, 96, 5925

Murchie, S. L., Thomas, P. C., Rivkin, A. S., \& Chabot, N. L. 2015, in Asteroids VI, ed. P. Michel, F. E. DeMeo, \& W. F. Bottke (Tucson, AZ: Univ. Arizona Press), 451

Nagashima, K., Moriuchi, Y., Tsukamoto, K., Tanaka, K. K., \& Kobatake, H. 2008, JMPeS, 103, 204

Nagashima, K., Tsukamoto, K., Satoh, H., Kobatake, H., \& Dold, P. 2006 JCrGr, 293, 193

Nishinaga, T. 2014, Handbook of Crystal Growth: Fundamentals (Amsterdam: Elsevier)

Nuth, J. A., III, Johnson, N. M., \& Manning, S. 2008, ApJL, 673, L225

Pasek, M. A., Milsom, J. A., Ciesla, F. J., et al. 2005, Icar, 175, 1

Pignatale, F. C., Liffman, K., Maddison, S. T., \& Brooks, G. 2016, MNRAS, 457, 1359

Pignatale, F. C., Maddison, S. T., Taquet, V., Brooks, G., \& Liffman, K. 2011, MNRAS, 414, 2386

Pizzarello, S., Cooper, G. W., \& Flynn, G. J. 2006, in Meteorites and the Early Solar System II, ed. D. S. Lauretta \& H. Y. McSween (Tucson, AZ: Univ. Arizona Press), 625

Raymond, S. N., \& Izidoro, A. 2017, Icar, 297, 134

Rivkin, A. S., Brown, R. H., Trilling, D. E., Bell, J. F., \& Plassmann, J. H. 2002, Icar, 156, 64

Roine, A. 2014, Outotec's HSC 8.0 Chemistry Software, https://www.outotec. com/globalassets/products/digital-solutions/hsc/whats_new_in_hsc_ 8.pdf

Ronnet, T., Vernazza, P., Mousis, O., et al. 2016, ApJ, 828, 109

Rosenblatt, P. 2011, A\&ARv, 19, 44

Rosenblatt, P., Charnoz, S., Dunseath, K. M., et al. 2016, NatGe, 9, 581

Salisbury, J. W., \& Walter, L. S. 1989, JGR, 94, 9192

Sekine, Y., Sugita, S., Shido, T., et al. 2006, M\&PS, 41, 715

Singer, R. B. 1981, JGR, 86, 7967

Visscher, C., \& Fegley, B., Jr. 2013, ApJL, 767, L12

Wasson, J. T., \& Kallemeyn, G. W. 1988, RSPTA, 325, 535

White, W., Johnson, S., \& Dantzig, G. 1958, JChPh, 28, 751

Wooden, D. H. 2008, in Origin and Early Evolution of Comet Nuclei, ed. H. Balsiger et al. (New York: Springer), 75

Yoneda, S., \& Grossman, L. 1995, GeCoA, 59, 3413

Zimmerman, W., \& Bukur, D. 1990, CJChE, 68, 292 